\title{
Making a CASE for Using the Students Choice of Software or Systems Development Tools
}

\author{
Barbara Howell \\ Leeds Metropolitan University, Leeds, United Kingdom
}

\section{B.Howell@LeedsMet.ac.uk}

\begin{abstract}
This positioning paper focuses on the selection of software for educational purposes and how the selection process may encourage usage. Computer Aided Software or Systems Engineering (CASE) tools provided an appropriate e software example for this study. The paper also seeks to examine if the use of Information Communication Technology (ICT) such as CASE can aid the students' understanding of systems analysis and design techniques. Entity relationship modelling has been used as the primary technique. Focus groups comprising postgraduate and undergraduate students were used as the main data collection instrument supported by a pre and post assessment test.

The findings provided a clear indication of which CASE tool the participants found easiest to use and which tool they were interested in using. It was further found that some tools have unique properties that may assist the user in their understanding. This paper also provides a valuable platform for defining future research in this area.
\end{abstract}

Keywords: CASE Tools. Systems Analysis \& Design, Focus Groups, ICT

\section{Introduction}

This paper outlines the first stages of a major research project. The paper describes an evaluation of a method by which a software product such as a Computer-Aided Software or Systems Engineering (CASE) tool may be selected for adoption within an educational institution. Furthermore, the paper seeks to establish which tool is the easiest to use and which provokes interest. This research exercise was not intended to refute the fundamental purpose of CASE tools but in addition to ease and interest sought to examine if the use of Information Communication Technology (ICT) in the form of a CASE tool can facilitate a students' understanding of a specific systems analysis and design technique. Based on these evaluations establish if a particular CASE tool could be a useful components of teaching and learning in relation to usability (ease of use), level of interest and facilitation.

Material published as part of this journal, either on-line or in print, is copyrighted by Informing Science. Permission to make digital or paper copy of part or all of these works for personal or classroom use is granted without fee provided that the copies are not made or distributed for profit or commercial advantage AND that copies 1) bear this notice in full and 2) give the full citation on the first page. It is permissible to abstract these works so long as credit is given. To copy in all other cases or to republish or to post on a server or to redistribute to lists requires specific permission from the publisher at Publisher@InformingScience.org

\section{Rationale}

The School of Information Management, Leeds Metropolitan University, United Kingdom, is in the process of adopting a new CASE tool to support the learning and teaching of various stages of the software development life cycle. To assist the selection proc- 
ess the user (students are the primary users), are to provide their views on desirable and undesirable characteristics of the tools. If users are involved in the selection process it is asserted that they are more likely to use the tool (Pressman, 1993). In addition, the academic teaching team have found that both undergraduate and postgraduate students have difficulty in grasping the syntax and semantics of systems analysis and design techniques. Peter Chalk (2000) states that CASE tools can enhance learning and support student centred learning. Both are desirable outcomes, which need to be explored and confirmed.

\section{CASE Tools}

CASE tools are automated software used by systems analysts on small and large scale information systems development projects (Chalk, 2000). CASE tools can provide support for a range of systems development tasks from project identification and selection to the implementation and maintenances phases (Hoffer, George \& Valacich, 1999). CASE tools can support one specific systems development methodology or a variety of approaches (Sommerville, 2001). In association with the organisations 'chosen' methodology, they help the analyst create systems models (many of them graphical models) and then automatically check the models for completeness and compatibility (Satzinger, Jackson \& Burd, 2002). CASE tools can also be categorised as upper, lower or integrated CASE tools (Satzinger et al., 2002). Upper CASE tools support the project identification, selection, planning, analysis and design phases of the systems development life cycle. Lower CASE tools provide support for the implementation, generating of code and maintenance stages of the systems development life cycle. The third category, integrated or ICASE tools combine the features of the upper and lower CASE tools to provide support for the full life cycle. For simplicity any future reference to CASE tools will be inclusive of the ICASE definition.

The rationale for using a CASE tool varies enormously between the various stakeholders. From the systems analysts perspective the reason for using a CASE tool are generally very practical and focus on making life easier (Parkinson, 1991). From an organisation perspective, the rationale is much broader and includes; improvement in the quality of the systems development, helps standardisation, improves the management of projects, simplifies maintenance, promotes reusability, improves the quality and maintenance of documentation and increases productivity (Hoffer et al., 1999). CASE tools must also be faster than using pencil and paper and be usable in developing a first draft diagram, which may not require consistency checking (Robinson, 1992). However, the selection of a CASE tool for many professional development environments is largely dependent upon the hardware platform, software system and skill base of the development engineers (Barn, 1992). For multi-national software companies, the mandate may come from a part of the corporation with no regard for the appropriateness of the tool for different kinds of project or domain. Kilov \& Ross (1994) assert that choosing one perfect tool is problematic and the expectation should be to choose a tool that might help.

When choosing a CASE tool for learning and teaching systems analysis and design techniques within an academic institution the hardware platform, operating system and availability of technical/administration resources are less likely to be an issue. Larger educational institutions, in particular those that teach within the computing discipline, for example, Leeds Metropolitan University, tend to have a variety of hardware platforms, operating systems and qualified technical/administration teams to support the broad range of software applications they require for learning, teaching and research purposes. The selection would therefore generally be based on the experiences and views of the academic or academics designated to teach the tool and their appreciation of its use in industry. These experiences and views although valuable will tend to be subjective in nature and at best qualitative evaluations. Therefore this paper asserts that choosing a particular tool should not be based on these views alone. This paper further asserts that many 
comprehensive tools are now available, for example, Select, Rational Rose and Together, with the majority supporting the rationale for usage by the organisation or the analyst. Therefore teaching a 'specific' tool is less important, particularly in a constantly changing technological environment than teaching the constructs of systems analysis and design techniques and the concept of CASE tools in general.

For the purposes of this exercise the selection method will therefore include the views of the students. It is suggested that the students are more likely to use a tool if they are part of the selection process. It is further suggested that the students are more likely to select and hence want to use a particular tool if they perceive it to be of benefit e.g. it makes drawing a particular model easier or it helps their understanding. This suggestion has beneficial properties for both the student and the educationalist. For the student, as a consequence of using the tool it may assist in their understanding of the theory of a modelling technique and develop a greater depth of understanding into how the tool operates. For the educationalist, if the tool is easy to use and hence learn, time may be spent on teaching the technique rather than the tool.

\section{Entity Relationship Modelling}

Entity relationship modelling requires the student to capture and express the relationship between data in an organisation or a concept of a system or process in diagrammatic form. These diagrams require an appreciation of three main constructs, entities in the business environment, the relationships or associations among those entities, and the attributes or properties of both the entities and relationships. Apart from this appreciation and the correct notation to be used to express the model the relationship between the entities poses three characteristics, which also require comprehension:

1. The relationship has binary properties, with every relationship between two entities consisting of two links, one in each direction. For example, if customer and order are two entities of interest to the organisation, a customer places an order describes the link in one direction. Similarly, an order is placed by a customer describes the link in the other directions.

2. The relationship has a degree or cardinality for each of the two links. For example, a customer might place one or more orders, but for the reverse link an order is placed by only one customer.

3. The relationship between two entities can be optional or mandatory, which is sometimes referred to as membership class. If it possible under any circumstances for an entity to exist without being related to the other entity, the relationship is described as optional conversely it will be mandatory. For example, customers may exist in some systems without placing an order (the relationship is optional), but an order cannot exist without being placed by a customer (the relationship is mandatory).

One further concept that sometimes applies in the development of a model is that many to many relationships are not allowed between two entities. The students can often find this concept and an appreciation of the bi-directional relationship the most difficult to understand and reproduce. An entity, which may be of interest to the organisation and the attributes the organisation may wish to record about that entity usually, prove less difficult to recognise and represent.

\section{Methodology}

The first stage of this research exercise involved selecting the CASE tools. The tools were selected for two main reasons. Firstly, they support the schools current teaching of systems analysis 
and design techniques more specifically entity relationship modelling developed using the crows foot notation. Secondly, they exhibited three very different approaches in the reproduction of an entity relationship model. The three CASE tools selected for this particular stage of the research exercise were Visio, Systems Architect and Web Engineer. Visio it not a true CASE tool however is used as a drawing tool that analysts use for a range of systems diagrams (Robson, 2000).

The second stage of this exercise involved setting up focus groups. Two distinct sessions were organised, the first session comprised postgraduate students and was conducted some weeks earlier than the second session, which comprised undergraduate students. The operation of distinct sessions at dispersed time scales facilitated an evolutionary approach to the sessions and the overall methodology of the research exercise. Based on the findings of the first session (Howell, 2003), it was concluded that the recording of the session should be extended to include the demonstration element and hence enable further abstraction of questioning and exploratory behaviour. Furthermore, the CASE tools appeared to modify the participants understanding of the entity relationship concepts. To confirm if the tools had changed their understanding, the level of this change and if possible to identify specific aspects of this change a test was introduced for the undergraduate session. The participants for this session completed two multiple-choice tests. One test was presented for completion prior to the session and one immediately after the session. Both tests comprised the same eight multiple-choice questions aimed at assessing the participants understanding of the entity relationship constructs. More specifically the test examined their understanding of optionality, cardinality, primary keys and definitions.

Focus groups were used as the main data collection instrument for the following reasons. First and foremost this study sought to generate a set of observations for three software products from a novice users' (unfamiliar with any CASE tool) perspective. Robson (2000) suggest that focus groups are a suitable mechanism for diagnosing the potential for problems with a new product and generating impressions of a product. Stapleton \& Williams (1992) state that, "short of getting undergraduates to actually use software it is sometimes difficult to see things from the novice's perspective". The focus group therefore comprised a sub-set of students who are by definition novice users, taken from a population of approximately twenty postgraduate and two hundred and fifty undergraduate students who have not used a CASE tool before but have some understanding of the technique. Secondly, to gain an understanding of how the participants might react to the tools (Anderson, 1998). Thirdly, discussion between the potential users would assist in developing a consensus of views. Focus groups enable interactions between the participants rather than the interviewer, such that the views of the participants can emerge (Draper, 1998). They also provide a greater depth and breadth of response (Bertrand, Brown \& Ward, 1992; Lewis, 1992). Finally, fixed questions may have provided easier to use results, however they would not permit the development of emergent issues to surface (Flores \& Alonso, 1995).

Focus groups can comprise a range of homogenous attributes for example, sex, age, marital status and socio-economic status (Morgan, 1996). For this enquiry using groups that were homogenous rather than mixed with regard to sex, age and marital status etc., was not seen as feasible due to the size of the population and more importantly not seen as necessary for this particular topic area. Postgraduate and undergraduate students studying Information Systems in the School of Information Management, Leeds Metropolitan University, United Kingdom, volunteered to take part from an approximate population of twenty postgraduate and two hundred and fifty undergraduate students. Segmentation of the volunteers was therefore confined to the academic level of the students, with the volunteers divided into, postgraduate and undergraduate. There is also some debate whether the population should know each other (Agar \& MacDonald, 1995; Stapleton \& Williams, 1992). This study comprised of individuals who all knew each other and in all probability were friends, as this would encourage a lively conversation (Agar \& MacDonald, 1995). 
The focus group session was broken down into six parts. Each CASE tool was demonstrated first and then discussed. By the end of each demonstration it was hoped that the participating students could draw two entities, label those entities, join the two entities together with a relationship line, label the relationship line, modify the relationship line in relation to cardinality and optionality, and attach attributes to the two entities. For this particular example, the diagram should illustrate that a customer entity must place one or more orders and the order entity must be placed by only one customer (see Figure 1). Although the model is relatively simple in form the exercise contained all the constructs required for the representation of a larger system using this technique and the problematic concepts discussed earlier.

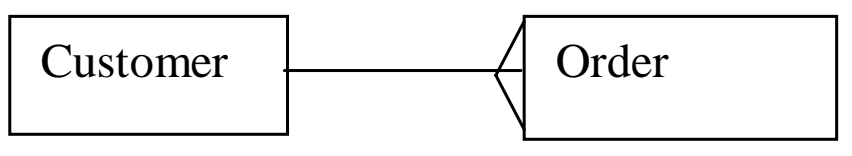

Figure 1. Entity Relationship Model

After each demonstration the participants were asked what they liked about the piece of software, what they disliked about the piece of software and if the software helped their understanding of the entity relationship modelling technique. This enabled a discussion between participants who had all experienced the same level of learning and teaching of the tool in the development of the same model. To codify the discussion and retrieve subsequent codified units NVivo software was used.

\section{Findings}

The findings have been broken down into two sections. The first section will present the findings from the focus group sessions and the second section will examine the results of the pre and post test.

\section{Focus Group Findings}

In order to analyse the focus group sessions the majority of comments have been abstracted and categories under the following headings:

Positive

Negative

Helped understanding

Not helped understanding

Questioning 


\section{Exploring}

General

Leading positive

Leading negative

In total, one hundred and twenty four comments were categorised from the postgraduate session, which comprised six participants. The categorisation of comments occurred as part of transcription process. Initially this research exercise had not sought to document exploratory and questioning comments. During the questioning phase of the session (the only element recorded for the postgraduate session) the students continued to engage with the software and hence continued to ask questions which related to the use of the software. This exploratory and questioning behaviour, although relatively anecdotal evidence at this time, could indicate the level of interest the participants showed in a particular tool. The associated comments, which were based on this unexpected activity during the session, were limited to the duration of the discussion, therefore provoking the recording of the whole of undergraduate session. The undergraduate session also comprised six participants.

The extension to the recording for the undergraduate session also provided an extended opportunity to examine the participants' behaviour during the instruction element. The recordings for the

Table 1. Summary of comments made by focus group participants

\begin{tabular}{|c|c|c|c|c|c|c|}
\hline & & $\begin{array}{l}\text { Positive } \\
\text { comment }\end{array}$ & $\begin{array}{l}\text { Negative } \\
\text { comment }\end{array}$ & $\begin{array}{l}\text { Helped to } \\
\text { understand }\end{array}$ & Clarification & $\begin{array}{l}\text { Questioning } \\
\text { /Exploring }\end{array}$ \\
\hline \multirow[t]{3}{*}{ Visio } & $\begin{array}{l}\text { Postgraduate } \\
\left.\text { (1 }{ }^{\text {st }} \text { session }\right)\end{array}$ & $28(6)$ & 7 (3) & $7(3)$ & - & $11(5)$ \\
\hline & $\begin{array}{l}\text { Undergraduate } \\
\left(2^{\text {nd }} \text { session }\right)\end{array}$ & $24(3)$ & $0(0)$ & $0(0)$ & $14(3)$ & $1(1)$ \\
\hline & Total & $52(9)$ & 7 (3) & $7(3)$ & $14(3)$ & $12(6)$ \\
\hline \multirow[t]{3}{*}{$\begin{array}{l}\text { Systems } \\
\text { Architect }\end{array}$} & $\begin{array}{l}\text { Postgraduate } \\
\left.\text { (1 } 1^{\text {st }} \text { session }\right)\end{array}$ & $6(3)$ & $6(3)$ & $1(1)$ & - & $11(5)$ \\
\hline & $\begin{array}{l}\text { Undergraduate } \\
\left(2^{\text {nd }} \text { session }\right)\end{array}$ & $5(2)$ & $18(5)$ & $0(0)$ & $24(4)$ & $11(4)$ \\
\hline & Total & $11(5)$ & $24(8)$ & $1(1)$ & $24(4)$ & $22(9)$ \\
\hline \multirow[t]{3}{*}{$\begin{array}{l}\text { Web } \\
\text { Engineer }\end{array}$} & $\begin{array}{l}\text { Postgraduate } \\
\left.\text { ( } 1^{\text {st }} \text { session }\right)\end{array}$ & $7(5)$ & $3(2)$ & $5(3)$ & - & 7 (3) \\
\hline & $\begin{array}{l}\text { Undergraduate } \\
\text { (2 }{ }^{\text {nd }} \text { session) }\end{array}$ & $17(5)$ & $16(3)$ & $4(2)$ & $15(5)$ & $4(2)$ \\
\hline & Total & $24(10)$ & $19(5)$ & $9(5)$ & $15(5)$ & $11(5)$ \\
\hline
\end{tabular}

(Note: The first figure indicates the total comments and the second figure in parenthesis indicated the number of participants who made those comments.) 
undergraduate session therefore documents when the participant's asked questions to clarify the instruction given or verify their actions. These comments have been categorised as 'clarification' comments. In total, one hundred and sixty five comments have been categorised for this session. However only those comments, which related to aspects, which were positive, negative, helped their understanding of entity relationship modelling, clarification and questioning or exploratory have been tabulated as per Table 1. These total, two hundred and fifty for both the postgraduate and undergraduate session.

Leading comments, both negative and positive by the facilitator were documented to establish if the participants' views might be open to bias. The nature of these comments, the context of the comment and the limited number of comments were not seen as having an impact on the results.

\section{Positive comments}

The first question posed to the participants of sessions following the demonstration phase was, 'what did you like about the software application you have just used'. The participants were also asked to make comment after they had experienced all three packages. The following are an abstraction of key issues from the sessions as a whole.

Comments made by postgraduate participants in relation to Visio include:

"It is user friendly and easy".

"I particularly like that when I looked at the bottom of screen and we started putting attributes in and that reminded me very much of an access database set up chart at the bottom of it."

“...bit more like my experience of using computers...”

"It looks more grown up - when you see this sort of blue and yellow, that's business like - more business like”.

"You know exactly - what you see is what you get kind of thing isn't it. It is very clear that you give something a name and attributes".

Comments made by postgraduate participants in relation to Systems Architect include:

"If you look at the big picture in years to come it's probably going to be the best oneisn't it. Because of the sheer things you can do with it".

"...I think with time you could get used to using this and I like - I have used visual basic

- so I like the way the screens are sectioned".

Comments made by the postgraduate participants in relation to Web Engineer include:

"It's simplistic - much easier to use that the other one".

"This is more flexible"

Comments made by the undergraduate participants in relation to Visio include:

"This one is more visual you can actually see everything - the definition of the categories it's real..."

“..it is not dissimilar to the other one you can only do one side"

Comments made by the undergraduate participants in relation to Systems Architect include: -

"It's got more options"

"It is useful because you know exactly what mode you are in" 
Comments made by the undergraduate participants in relation to Web Engineer include:

"Its just using the common windows commands isn't it. Using the right click to add it"

"There is less chance to made a mistake"

In general Visio received more positive comments that the other two CASE tools (see Table 1), with the majority of the participants finding the tool clear, easy to use and familiar to other software applications. Web Engineer was found to be generally easier and less confusing to use than Systems Architect. The participants did however observe that Web Engineer could not support UML modelling which may have inhibited more positive comment. Alternatively, the participants agreed that Systems Architect might have beneficial properties for the more experienced user. Based on the postgraduate session alone, Visio was the first tool to be demonstrated and discussed therefore the participants may have been more enthusiastic with the CASE concept rather than the specific tool at the start of the session, with this enthusiasm declining towards the end of the session. However, Visio was the last tool to be demonstrated and discussed during the undergraduate session and the same argument could be made for this positioning, thus negating the previous assertion.

\section{Negative Comments}

The second question posed to the participants of the sessions was, "is there anything you did not like about the software application you have just used”. Again the participants continued to make comment after all three CASE tools had been presented. The following documents some of the key negative issues from the sessions as a whole:

Comments made by participants in relation to Visio include:

"It's not easy to modify"

"If you want it bigger - you can't drag it to make it bigger"

Comments made by participants in relation to Systems Architect include:

"It's a lot more complicated"

"I think it is too complicated - too advanced"

Comments made by participants in relation to Web Engineer include:

"If you had a tutorial with it .. then you could actually do a tutorial step by step"

"Tatty line"

Comments made by the undergraduate participants in relation to Visio - none

Comments made by the undergraduate participants in relation to Systems Architect include:

"It takes ages to load"

"The fact that you can only put one name on it"

Comments made by the undergraduate participants in relation to Web Engineer include:

“The start up - starting it up - that wasn't right easy was it - if you don't know what you are doing"

"When you want to rename the whole thing"

The Visio CASE tool did not exhibit exactly the same notation as was expected for the postgraduate session. This was due to an inability to modify the master templates once the software 
had been installed. The negative comments in relation to Visio were generally based on this inability. This issue was easily resolved and the participants of the undergraduate session did not experience any problems with the templates. By the elimination of this solvable issue, Systems Architect was overall found the most difficult to use (see Table 1). The undergraduate participants did not make any negative comments in relation to Visio.

\section{Helped understanding of modelling technique}

The third and final question presented to the participants was, "if the software package helped their understanding of the entity relationship modelling technique”. The following are a selection of views in direct response to this question.

Comments made by postgraduate participants in relation to Visio include:

"Something to start off with..."

"I think that it - I mean how do we make a neat drawing - if we don't have something like this".

"Labelling the text boxes".

Comment made by postgraduate participants in relation to Systems Architect includes:

"It has enhanced your knowledge as well - the many to many thing as well but you have to know what you are doing"

Comments made by postgraduate participants in relation to Web Engineer include:

"It's a lot easier - personally I find this one a lot easier"

"It helps you in that you see the point of what you are trying to do"

"On the very last one I get really confused about which end I should stick the O for optionality - I read it backwards and forwards dozens of times and still sounds right which ever end I put the zero on - so that was good in a way because it did reinforce that - if you read this way this is the bit that is the option bit - that was actually helpful..."

Comments made by the undergraduate participants in relation to Visio - none

Comment made by the undergraduate participants in relation to Web Engineer includes:

"It's quite logical - it is what you have taught us"

Comments made by the undergraduate participants in relation to Systems Architect - none

It is generally accepted that CASE tools assist in the production of a model and make revisions easier (Stapleton \& Williams, 1992; Wetherbe \& Vitalari 1994). The above comments would certainly confirm this assertion with Visio found to be the easiest to use and Web Engineer a close second. The participants viewed ease of use as facilitating their understanding because it took less time to produce a clear and understandable diagram.

Two of the CASE tools posed certain constraints on how the model is constructed and these constraints proved particularly noteworthy as an aid to understanding. Systems Architect poses extra demands on the user in determining the type of relationship. This demand required an appreciation of cardinality and optionality before the model is drawn. The participants found this feature particular supportive in assisting their understanding of those constructs. Whist Web Engineer facilitated their understanding of the binary properties of the relationship (see Figure 2). The modification of cardinality and optionality can only be performed in a particular way assisting 
their understanding of the direction of the relationship. Overall Web Engineer was found to be particularly helpful for the development of the entity relationship model.

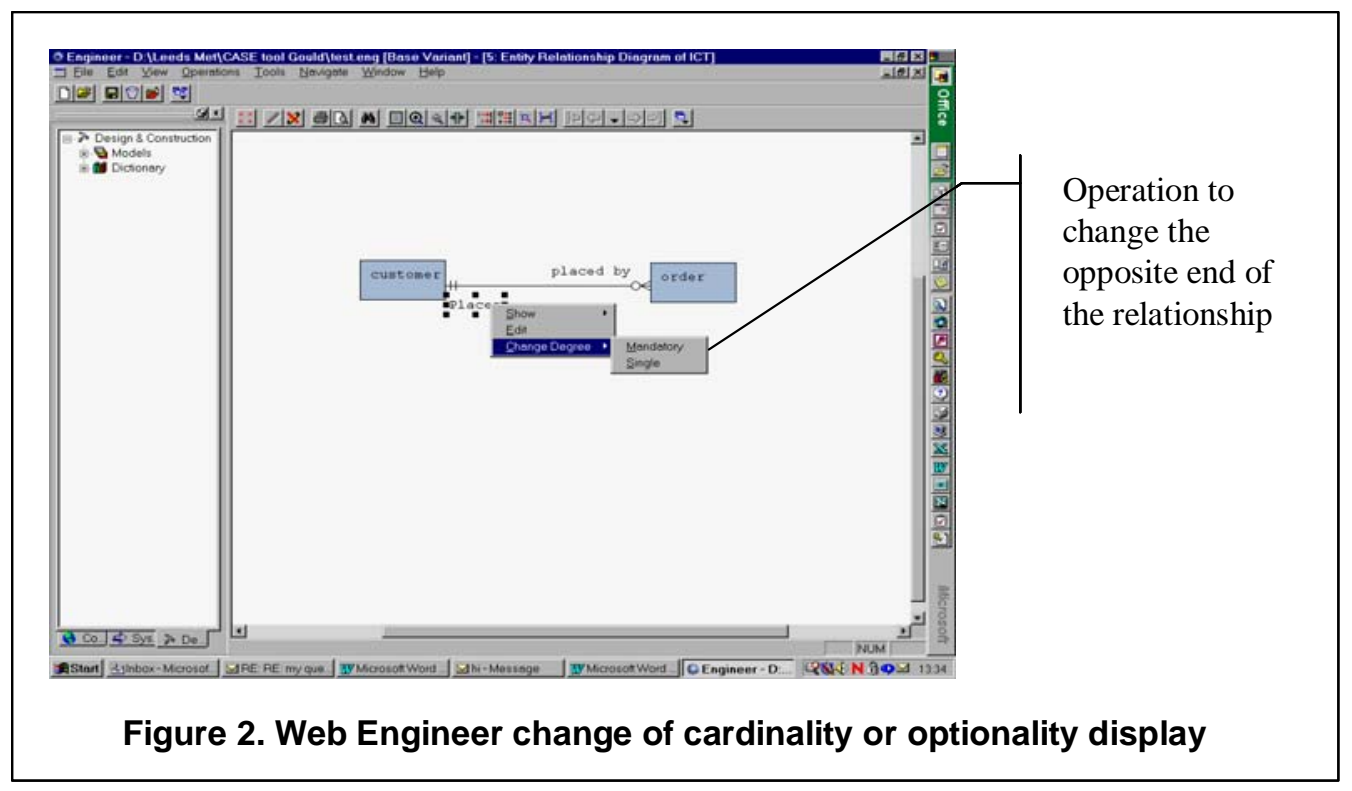

\section{Questioning or exploratory comments}

The demonstration phase of the postgraduate session were not taped, however during the discussion phase, which was taped, the participants continued to show interest in the CASE tools and it was sometimes difficult to draw them away. Hence the recording included some intermittent comments disassociated to the three key questions. The undergraduate session, which recorded both the demonstration and the discussion phase, provided a further opportunity to abstract such comments. These unsolicited comments have been documented as they could be seen as anecdotal evidence of the level of interest the participants showed in a particular tool. The comments have been classified as either exploratory or questioning, however the two groupings have been combined, as the differences between the terms are less significant than their cumulative support. The following are a representation of some of the key comments within this grouping:

Comments made by postgraduate participants in relation to Visio include:

"So can you do it vice versa if you want - do your database."

"Is their text direction in this?"

"This USECASE - how does that relate to this or the UML, within Visio"

Comment made by postgraduate participants in relation to Systems Architect includes:

"Can I edit this and change these?"

Comments made by postgraduate participants in relation to Web Engineer include:

"So how does it implement the many to many relationships?"

"What is a way point?"

Comment made by the undergraduate participants in relation to Visio includes:

“There is a reason for that?" 
Comment made by the undergraduate participants in relation to Systems Architect includes:

"Can you make the wording resemble the size of the box?"

"Is this for our data flow diagram?"

"Is this just for now or will I be able to put another in?"

"Why has it got a border round it?"

Comments made by the undergraduate participants in relation to Web Engineer include:

"Can you move it"

"Can you pull that away and follow it"

"Is it this tool that does the DFD's"

The above evidence, the total number of comments made and the total number of participants making those comments for the postgraduate session as per table 1, reflect a higher level of interest for Visio and Systems Architect. Again these findings could be a result of the organisation of the postgraduate session in relation to Visio as this was demonstrated first. However, yet again the same conclusions cannot be drawn from the undergraduate session with Systems Architect receiving the most comments and the second tool to be demonstrated. As Systems Architect received the majority of questioning and exploring comments overall this could indicate that it was of interest to the participants. In order to clarify this assertion the participants would have to be questioned as to what the questioning or exploratory behaviour actually indicated.

\section{Clarification comments}

As the undergraduate session recorded the demonstration phase of the session it was also possible to abstract comments, which could be interpreted as clarification comments. This type of comment could indicate the degree of difficulty the participants experienced with each CASE tool during the demonstration phase of the session. Comments classified under this heading were those, which provided an affirmation of the participants' actions or a request for confirmation of the instructions given. The abstracted comments have been totalled and the number of comments per participant has been calculated. These calculations have been used as a measure of ease of use. The following are example of such comments:

Comments made by the undergraduate participants in relation to Visio include:

“And put a name on it?”

"This at the top?"

Comments made by the undergraduate participants in relation to Systems Architect include:

"Is it meant to be grey, yes?"

"That says entity?"

Comments made by the undergraduate participants in relation to Web Engineer include:

$$
\begin{aligned}
& \text { "In this box?" } \\
& \text { "Is that right?" }
\end{aligned}
$$

It was hoped that all presentations were given with the same coherence and level of detail therefore provoking equitable levels of clarification between the tools. If coherence was lacking or more detail was required for one tool more than another, this in itself could imply a difference in the degree of difficulty. Alternatively, a progressive reduction in difficulty could be the result of 
the participants becoming familiar with the some of the general CASE tool concepts. The number of participant requiring confirmation of their actions did reduce as the presentations progressed. However the tool presented second received sixty percent or more requests for clarifications than the tool presented first or last.

\section{Test Results}

The undergraduate session which included a pre and post test was completed by all of the participants. The results of the two tests were compared. Differences between the two tests were categorised as either a positive change, they got the question right for the second test, a negative change, they got the question wrong for the second test or neither positive or negative, they made a change which remained incorrect or correct. Some questions could have more than one correct answer.

Although positive alterations following the focus group session would seem the most desirable outcome, improved performance from the pre to post test alone was not perceived as particularly noteworthy for this particular research exercise. Therefore any alterations to an answer, be it positive, negative, neither positive nor negative have been recorded and evaluated to document all the changes of opinion made by the participants. See Table 2 for a summary of the changes made for each question.

\begin{tabular}{|c|c|c|c|c|c|}
\hline \multicolumn{5}{|c|}{ Table 2: Summary of changes made to each test question } & \multirow[b]{2}{*}{$\begin{array}{l}\text { Total per } \\
\text { Question }\end{array}$} \\
\hline $\begin{array}{l}\text { Question } \\
\text { number }\end{array}$ & Question Type & $\begin{array}{l}\text { Positive } \\
\text { Change }\end{array}$ & $\begin{array}{l}\text { Negative } \\
\text { Change }\end{array}$ & $\begin{array}{l}\text { Neither } \\
\text { Positive or } \\
\text { Negative } \\
\text { Change }\end{array}$ & \\
\hline Q1 & Optionality & 2 & 1 & 0 & 3 \\
\hline Q2 & Cardinality & 0 & 1 & 1 & 2 \\
\hline Q3 & $\begin{array}{l}\text { Optionality and } \\
\text { Cardinality }\end{array}$ & 1 & 0 & 0 & 1 \\
\hline Q4 & Cardinality & 1 & 0 & 2 & 3 \\
\hline Q5 & Primary Keys & 0 & 0 & 0 & 0 \\
\hline Q6 & Optionality & 1 & 0 & 0 & 1 \\
\hline Q7 & $\begin{array}{l}\text { Definition of an } \\
\text { Entity }\end{array}$ & 0 & 3 & 0 & 3 \\
\hline Q8 & $\begin{array}{l}\text { Optionality and } \\
\text { Cardinality }\end{array}$ & 0 & 1 & 0 & 1 \\
\hline Total & & 5 & 6 & 3 & 14 \\
\hline
\end{tabular}

The majority of the participants made at least two changes to the answers between the tests. For the two questions, which focused on optionality, half of the participants made an alteration to the answer and in all cases the change was a positive one. All the participants answered the primary key question correctly. For the question which related to the definition of a product, interestingly the majority of the participants defined the product as an Entity and/or an Entity Type, however half the participants altered their answer to "Data Type" as a possible definition. This negative change could directly be attributed to Visio, which uses the term. See Figure 3. 


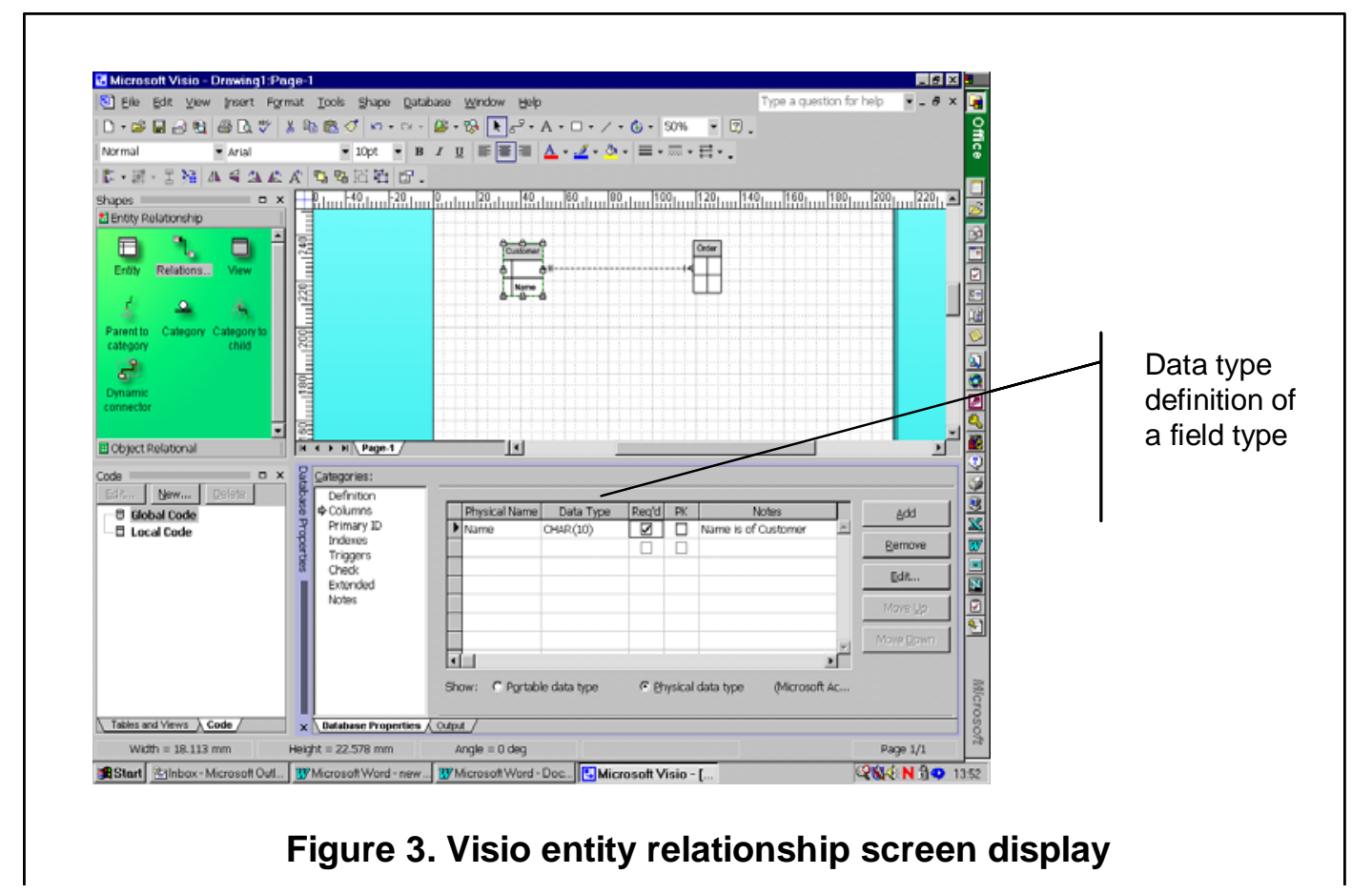

At this stage of the investigation the majority of the changes made by the participants could not be associated to one particular CASE tool as the test was completed after all three packages had been presented and discussed. The only observable exception is the relationship between the answer to question seven and Visio as reported above. It should also be noted that the diverse range of tools presented might have had a cumulative impact, which randomised the change a participant might make. Furthermore, the changes made by the participants' could also be attributed to guesswork for both tests.

\section{Discussion}

Many aspects of this research exercise have posed additional questions a change of methodology and several interesting aspects worth evaluating and/or recording for future studies. For clarity this section has been broken down into four section, methodology, focus group findings, test results and summary.

\section{Methodology}

The focus group methodology was a useful mechanism in the evaluation of the CASE tools. It is also well worth noting that the methodology was successful in developing enthusiasm of systems analysis and design amongst the participants. With regard to the organisation, the emphasis was on "emergence" with a shift in procedure from one session to another in order to optimise the abstraction of data. One further point to note was the codification and subsequent retrieval of the codified units. The categories were in part pre-determined in relation to the answers to the questions posed. However the richness of the generated data provoked post-conceptualisation of some valuable emergent categories for example exploratory and clarification comments. This methodology is a hybrid of the more simplified variety of analytical approaches as described by Lederman (1990), which do not seek to merge pre-determined and emergent categorisation. 


\section{Focus Group Findings}

The participant's of the first session were certainly the most vocal and were able to express their views with a higher level of clarity. The first group comprised of a more mature set of individuals as they were taken from the postgraduate student population. However both groups appreciated the role the individual tools could play. The majority of the participant's from both sessions gave favourable comments in relation to Visio. In relation to the original hypothesis, the findings indicate that they found the tool easy to use and would hence be more likely to use it and as a consequence it would assist their understanding of the entity relationship concepts. Conversely it is suggested that both sets of participants found Systems Architect of interest and engaged enthusiastically by actively exploring several features of the tool. In relation to understanding both groups found Web Engineer to contain one particular property, which aided their comprehension of the bi-directional aspect of a relationship.

\section{Test Results}

The experiences of the postgraduate session influenced the inclusion of a pre and post test for the undergraduate session. The test was introduced as a complementary analytical device to establish if the participants understanding of the entity relationship modelling constructs had changed in any way. The results although not conclusive at this preliminary stage of the research exercise are of particular interest and require further exploration. For example, several of the participant's changed their answer to the questions, which related to optionality. It is asserted that Web Engineer may have consciously or unconsciously facilitated this positive change. One further example is the change of answer to question seven and the answer change to "Data Type" as a definition. The recording for the session has been checked and the subsequent transcript and the term had not been referred to verbally during the session. The only reference to a "Data Type" can be found as a definition of a field type in Visio. This was also the last tool presented to the group therefore this message may have been relatively fresh in the minds of the participants. It is also worth noting that the test results would have improved overall had several of the respondents not made this negative change. However, to clarify if these changes are incidental or relate to a specific tool it is proposed to run a more comprehensive set of dedicated tests.

\section{Summary}

Based on the finding of the focus group sessions and test it is possible to make a first attempt at classifying the three tools. The classifications for the purposes of this exercise were usability, facilitation and level of interest as defined at the outset of research exercise. Although facilitation is probably not the most appropriate word for the classification as the focus was adapted during the study to investigate any change in understanding with the inclusion of the pre and post test. Furthermore, it has been possible to classify the level of interest based on the level of questioning and exploratory comments.

The usability ranking is attributed to the number and composition of positive, negative and clarification comment made by the participants. For example, Visio received the greatest number of positive comments, and the fewest negative and clarification comments. The views of the focus groups as a primary indicator (perceived as more reliable) and the results of the test as a secondary indicator (anecdotal evidence) have been used to determine the facilitation ranking. For example, both sets of participants found Web Engineer to assist their understanding as reported from the focus groups and the test results could also indicate some form of effect albeit subliminal, clearly suggesting it be ranked in first place. Level of interest is derived from the number and composition of the questioning and exploratory comments. See Table 3 for a tabulation of the classifications. 


\begin{tabular}{|lccc}
\hline \multicolumn{4}{|c|}{ Table 3. CASE tool classification table } \\
\hline & Usability & Facilitation & Level of Interest \\
\hline Visio & $1^{\text {st }}$ & $2^{\text {nd }}$ & $2^{\text {nd }}$ \\
\hline Web Engineer & $2^{\text {nd }}$ & $1^{\text {st }}$ & $3^{\text {rd }}$ \\
\hline Systems Architect & $3^{\text {rd }}$ & $3^{\text {rd }}$ & $1^{\text {st }}$ \\
\hline
\end{tabular}

\section{Conclusions}

It is acknowledged that the sample size is relatively small, and conclusions must be tempered accordingly, however it is asserted that the level of contribution from the participants provides ample ammunition for an enquiry in its first stages. Therefore in conclusion, the majority of the participants agreed that Visio would be a useful tool for students, in particular for those who are relatively new to the concepts. (Visio is one of the CASE tools to be used in the School of Information Management at Leeds Metropolitan University for the next teaching session.) They then agreed that although Systems Architect was difficult to use, it would be the best tool for those more familiar with the techniques. (Systems Architect is also to be made available to the students for the next teaching session.) It was further found that some CASE tools have unique properties that may assist the user in their understanding of the techniques. These properties were evident in Web Engineer. Furthermore, when evaluating the transcripts not only could an evaluation of the three main questions be abstracted it is suggested that it was possible to gauge the degree of enthusiasm the participants had with a particular tool by the level to which they wished to explore how it worked. Although this evidence was by no means conclusive it is an aspect that should be further explored with future focus groups.

The participants of the undergraduate session demonstrated a change in their understanding for specific concepts of the entity relationship modelling technique. To consolidate these finding future focus groups are required and the range of CASE tools is to be extended, as it may then be possible to find a tool that is both easy to use, facilitates understanding and encourages student centred learning. This assessment could also be associated with particular groupings of the tools associated to cost, memory requirements or operating capability e.g. standalone systems. Future research could also be extended to include more complex entity relationship modelling constructs and other modelling techniques. Focus group sessions could also be used to support the selection and procurement of a range of software applications for novice or student users to include programming, financial and statistical packages.

One final observation worthy of comment is the use of focus groups for learning and teaching. Although the participants were volunteers and were generally interested in the subject as a whole, overall they displayed relative apathy at the start of the session at the prospect of doing yet more entity models. During the session the abstraction of 'level of interest' comments recorded unsolicited dialogue and certainly by the end of both sessions the participants without exception continued to discuss CASE tools and modelling enthusiastically between themselves. For both sessions it proved extremely difficult to make closure. In addition, they continued lively conversations on the topic as they left the room and walked down to corridor. Their may therefore be value in exploring focus groups further for learning and teaching systems analysis and design techniques. 


\section{References}

Agar, M, \& MacDonald, J. (1995). Focus groups \& ethnography. Handbook of Applied Social Research Methods. 54, 78-86.

Anderson, G. (1998). Fundamentals of educational research. Falmer Press.

Barn, B. S. (1992). User interface development: Our experience with HP interface architecture. CASE Current Practices, Future Prospects, 4, 21-33. UK: John Wiley.

Bertrand, J, E., Brown J E., \& Ward, V. M. (1992). Techniques for analysing focus group data. Handbook of Applied Social Research Methods. 16, 198-209.

Chalk, P. (2000). Assessing student' learning when using software engineering webworlds. Retrieved January 18, 2003, from http://www.ics.ltsn.ac.uk/pub/conf2000/Papers/chalk.htm

Draper, S. W. (1998). Observing, measuring or evaluating courseware. Retrieved January 22, 2003, from http://staff.psy.gla.ac.uk/ steve/Eval.HE.html

Flores, J. G., \& Alonso C. G. (1995). Using focus groups in education research. Handbook of Applied Social Research Methods. 19, 84-101.

Hoffer, J. A., George, J. F \& Valacich, J. S. (1999). Modern systems analysis and design (2 ${ }^{\text {nd }}$ ed.). AddisonWesley Londman.

Howell, B. (2003). CASE Tools to support learning and teaching. How do you choose and use? In Proceedings of the $4^{\text {th }}$ Annual Conference of the LTSN Centre on the Teaching of Computing, Galway, Ireland. 26/28 ${ }^{\text {th }}$ August 2003.

Kilov, H., \& Ross, J. (1994). Information modelling. An object-oriented approach. Prentice Hall.

Lederman, L. C. (1990). Assessing educational effectiveness: The focus group interview as a technique for data collection. Communication Education. 38, 117-127.

Lewis, A. (1992). Group child interviews as a research tool. British Educational Research Journal. 18 (4), 413-421.

Morgan, D. L. (1996). Handbook of applied social research methods. 22, 129-152.

Parkinson, J. (1991). Making CASE work. N`CC Blackwell.

Pressman, R. S. (1993). A manger's guide to software engineering. McGraw-Hill.

Robinson, K. (1992). Putting the SE into CASE. In K. Spurr and P. Layzell (Eds.), CASE Current Practices, Future Prospects, 4, 1-20. UK: John Wiley.

Robson, C. (2000). Small-scale evaluation. Sage Publication.

Satzinger, J. W., Jackson, R. B., \& Burd, S. D. (2002). Systems analysis and design (2 ${ }^{\text {nd }}$ ed.). Thomson Learning.

Sommerville, I. (2001). Software engineering ( $6^{\text {th }}$ ed.). Addison-Wesley.

Stapleton, J. \& Williams, S. (1992). Experiences of introducing a CASE tool into undergraduate teaching of systems analysis and design. In K. Spurr and P. Layzell (Eds.), CASE Current Practices, Future Prospects, 4, 55-66. UK: John Wiley and Sons.

Wetherbe, J. C \& Vitalari, N. P. (1994). Systems analysis and design. Best practices (4 ${ }^{\text {th }}$ ed.). West Publishing.

\section{Biography}

Barbara Howell is a principal lecturer in the School of Information Management at Leeds Metropolitan University. She has been teaching in Higher Education for the past ten years and currently holds the post of course leader for a number of undergraduate Information Systems 
courses. She is actively engaged in research and published in the area of education, soft systems methods and CASE tools with recent research interests focusing more on CASE tools and the development of the Information Systems curriculum. 